\title{
High-frequency sulfur isotope variability in the Late Ordovician of the Cincinnati Region
}

\author{
WILLIAM GILHOOLY ${ }^{1}$, BROOKE VANDER PAS ${ }^{2}$, \\ EVELYNN BECERRA ${ }^{2}$, ALICE BOSCO-SANTOS ${ }^{3}$ AND \\ BEN DATTILO 4 \\ ${ }^{1}$ Indiana University Purdue University Indianapolis \\ ${ }^{2}$ Indiana University-Purdue University Indianapolis \\ ${ }^{3}$ University of Campinas \\ ${ }^{4}$ Purdue University Fort Wayne \\ Presenting Author: wgilhool@iupui.edu
}

The Ordovician period (485-444 Mya) was characterized by major climatic, geologic, and evolutionary change. The climatic transition from "hot-house" to "ice-house" conditions of the endOrdovician Hirnantian glaciation coincides with the loss of 60$70 \%$ of marine species, many of which first appeared during the Great Ordovician Biodiversification Event in the beginning of the period. We present chemostratigraphy from a succession of limestone and shale from the Katian interval (Upper Ordovician) of a Cincinnatian drillcore collected in Kentucky, USA. The interbedded mudstone-limestone succession may track variations in sedimentation associated with changes in water depth and shifts in the seafloor environment in response to sea level fluctuations. The carbonate carbon isotope excursions are coincident with previously published carbon isotope records generally thought to represent perturbations in the global carbon cycle. Uncoupled from global carbon cycling within this core is the observation of rapid alternations in sulfur isotope geochemistry on the order of millennial cycles. The sulfur isotope composition of chemically extracted pyrite show exceptional variability throughout the core with alternations that vary by as much as $50 \%$. The rate of change of systematic increases and decreases in sulfur isotope composition are inconsistent with global sulfur cycling. These results indicate that localized changes driven by diagenetic reactions during early burial strongly influence the sulfur isotope record in this locality. We further explore the constraints on this sulfur isotope record associated with nutrient ( $\mathrm{N}$ and $\mathrm{P}$ ) dynamics and diagenetic reactions associated with reactive iron availability framed within the context of biostratigraphy and petrography. 